\title{
A Case of Intolerable Pain due to Intradiscal Root Herniation and Entrapment Following Lumbar Surgery
}

\author{
Junseok W. Hur, Jang-Bo Lee, Yong Gu Chung, Jung Yul Park ${ }^{\bowtie}$ \\ Department of Neurosurgery, Korea University College of Medicine, Korea University Anam Hospital, Seoul, Korea
}

A 74-year-old female patient suffered unbearable pain and motor weakness that suddenly occurred 3 weeks after lumbar surgery. On magnetic resonance imaging, an unusual lesion was shown as intermediate signal intensity on T2 weighted image indicating neural components which has continuity from thecal sac to the disc space. Revision operation confirmed intradiscal root herniation and entrapment caused by underdiagnoses of suspicious of incidental ventral durotomy during previous surgery. Indirect dural repair with DuraSeal $^{\mathrm{TM}}$ and Gore-tex ${ }^{\circledR}$ was performed and marked improvement of preoperative pain and weakness were noted following surgery.

Key Words: Nerve entrapment; Herniation; Discectomy; Dura; Injury.

\ Corresponding author: Jung Yul Park, Department of Neurosurgery, Korea University College of Medicine, Korea University Anam Hospital, 73 Inchon-ro, Seongbuk-gu, Seoul 02841, Korea. Tel: 82-2-920-5729, Fax: 82-2-929-0629, E-mail: jypark98@korea.ac.kr

\section{INTRODUCTION}

Incidental durotomy after lumbar disc surgery is well known complication and reported up to $1.8-18.5 \%$ in various studies $^{4-6,9,10,12-17)}$. In some instances, durotomies are unrecognized during surgery and these could lead to a severe postoperative complication. We report a case of intolerable pain that occurred after lumbar surgery with unrecognized incidental durotomy and intradiscal herniation of nerve root.

\section{CASE}

A 74-year-old female patient was admitted from severe left lower extremity pain (VAS 9) and ankle weakness (dorsiflexion grade 0 , plantar-flexion grade 2 ) which started a week ago. She had no medical history besides hypertension but suffered from low back pain since 30 years ago. One month ago, she underwent lumbar 3/4 discectomy at other hospital as the diagnosis was herniated lumbar disc at L3/4. Subsequently, her symptom improved but after 3 weeks later, she complained of severe left lateral lower extremity pain and the ankle weakness. Postoperative magnetic resonance imaging (MRI) study (Fig. 1) was performed but the previous operator considered as negative finding and maintained medication and rehabilitation. The patient could not bear with the pain and there was no motor improvement. We performed electromyelography and found left L5 radiculopathy. We postulated that there was a remnant disc fragment on L3/4 level left side (Fig. 1, arrow) and underwent revision surgery. Contrary to our expectation, we found herniated roots in disc space rather than disc fragment (Fig. 2). Thecal sac defect was noted from the left side to the ventral portion and the end of ventral defect was not identified. We sealed the defect with Gore-tex ${ }^{\circledR}$ (W. L. Gore \& Associates Inc, Flagstaff, AZ, USA) graft and DuraSeal ${ }^{\mathrm{TM}}$ (Coviden, Waltham, MA, USA) (Fig. 3). Post-operatively, the severe pain subsided gradually and eliminated on post-operative day 7 . There was no cerebrospinal fluid (CSF) leakage and the wound healed without any complication. Six months after surgery, the patient was totally pain free and the left ankle motor improved (dorsi-flexion grade 4, plantar-flexion grade 4+).

\section{DISCUSSION}

Incidental durotomy could be notable during the surgery, but sometimes it is missed if not carefully inspected. Among unawared cases, some are solved with natural healing but some cases may lead to CSF leakage and furthermore, root herniation with entrapment could happen. Root herniation could oc- 
cur any side of thecal sac where the durotomy is made. In case of discectomy with accidental ventral durotomy, it could lead to intradiscal root herniation with entrapment. The incidence of this complication is not reported yet and there are only a few case reports of this condition ${ }^{3,18)}$. Intradiscal root herniation could be misdiagnosed as intrathecal disc herniation or underdiagnosed because of its unfamiliarity. It is important to aware of this condition with meticulous review of patient history, clinical features, and post-operative MRI findings.

Abrupt and severe pain subsequent to lumbar surgery is important clue especially if the symptom starts few days after surgery. If the pain aggravates immediate after surgery, surgeon should consider the possibility of remnant disc, neural damage during operation, or hematoma more carefuly. However, if the pain occurs after some interval, especially more than a week like our case and previous reports ${ }^{3,18)}$, neural entrapment syndrome should be considered, if not the cases of recurrent disc herniation. In addition, clinical feature is another important clue. Ahn et al. ${ }^{1)}$ summarized the typical symptoms of nerve root entrapment syndrome. It is characterized by relapse of in-

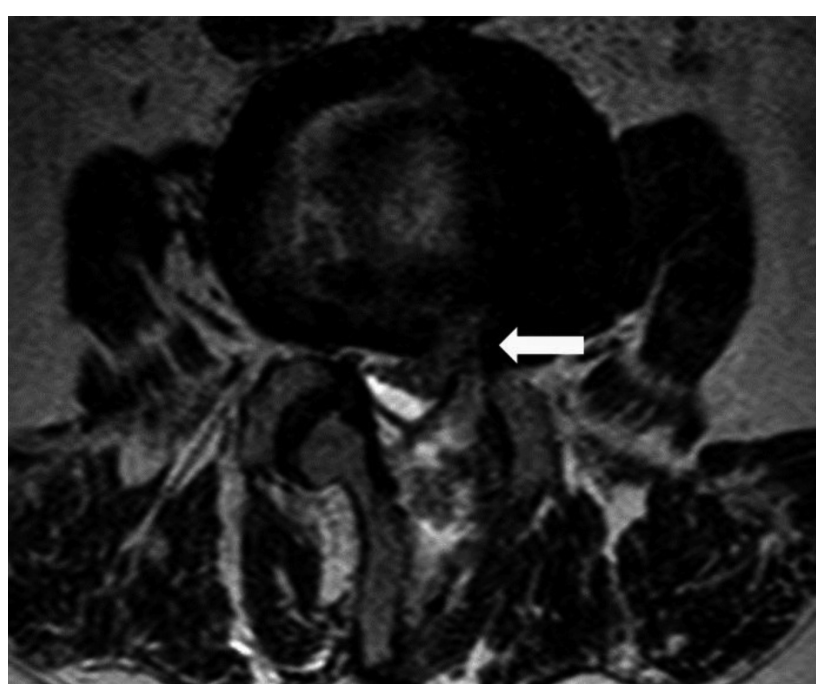

Fig. 1. T2 weighted axial MRI after previous surgery. Arrow indicates the herniated roots after disc space.

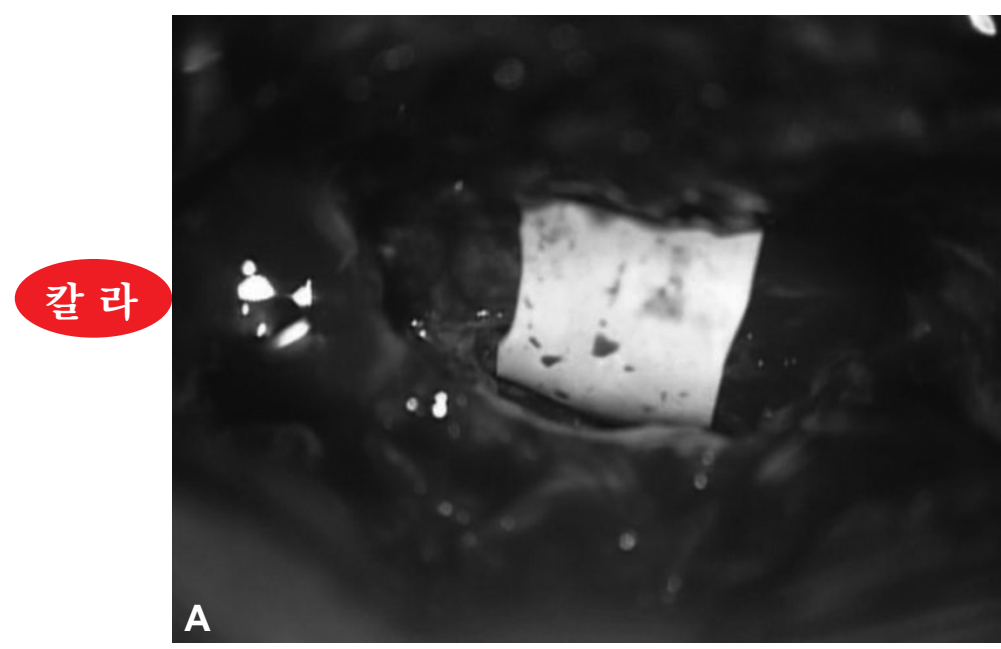

Fig. 3. Thecal sac and the herniated roots are covered with Gore-tex ${ }^{\circledR}$ graft $(A)$ and sealed with DuraSeal ${ }^{\mathrm{TM}}$ sealant $(B)$ tractable radicular pain that may be either dermatomal or no dermatomal, resembles electric shock in nature. The pain is aggravated by walking or position change and is accompanied by various neurologic deficits. For the present case, the patient had unbearable pain (VAS 9) even at the supine position and was impossible to walk because of aggravation. For the MRI findings, CSF fluid collection and continuity of neural components would be the evidence of intradiscal root herniation. The CSF fluid collection is most typical finding in most of the dural injury cases. It may be collected in disc space or form pseudomeningocele dorsal to the thecal $\mathrm{sac}^{2)}$. For the image of neural components, Bae et al. ${ }^{3)}$ suggested that the nerve root displacement could be observed like a shape of gull's wing on sagittal MRI. Additionally, we suggest one of the most important MRI finding would be the intermediate signal and continuity of nerve roots from the thecal sac to the disc space on $\mathrm{T} 2$ weighted axial image (Fig. 2). It is a good indicator to distinguish with intrathecal disc herniation which shows low signal intensity on T1 and $\mathrm{T} 2$ weighted $\mathrm{MRI}^{8}$.

Standard method for dural tear repair is primary suture with or without sealants augmentation ${ }^{7,11}$. If the durotomy is in lateral or dorsal side of thecal sac, it could be handled with stan-

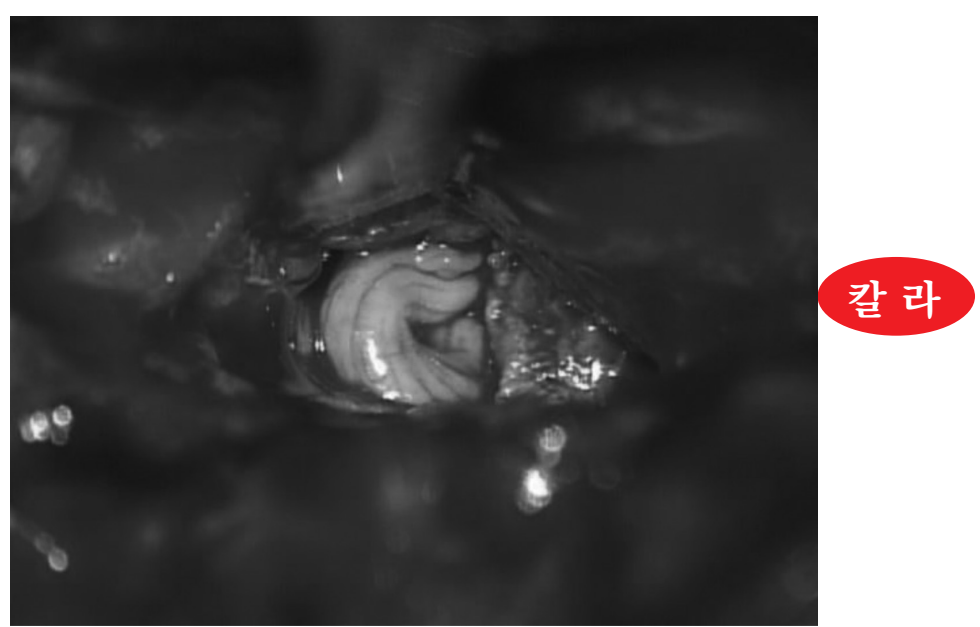

Fig. 2. Microscopic view of herniated swollen root.

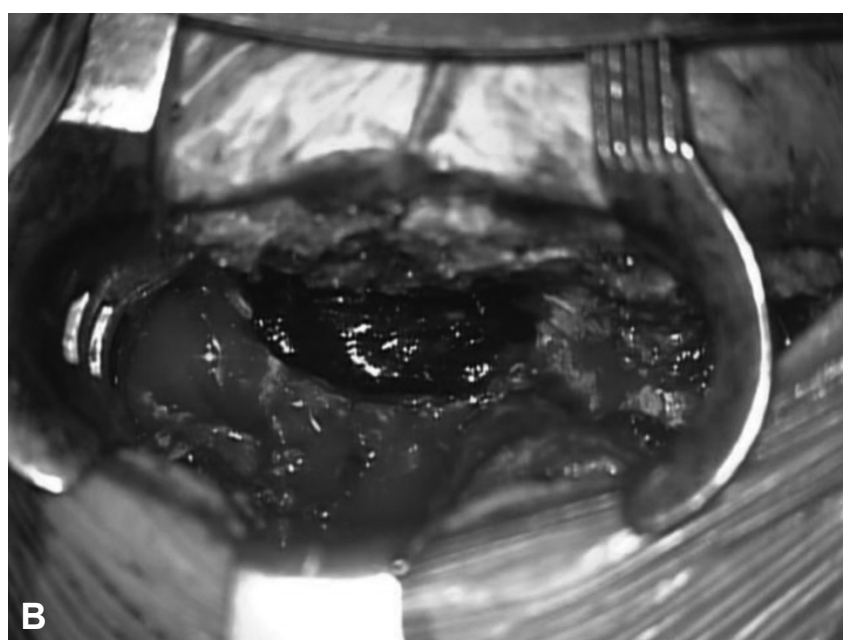

B$$
\text { (B). }
$$ 
dard method but if the dural tear occurred in the ventral side, the repair could be complicated. One way is to repair through dorsal dura making an additional incision. However, this approach may be much burden for surgeon and occasionally cause unfavorable results in spite of the efforts. In our case, we used Gore-tex ${ }^{\circledR}$ to cover the defect and sealed with DuraSeal ${ }^{\mathrm{TM}}$ instead of suturing method. Intra-operative Valsalva showed no evidence of CSF leakage and post-operative drainage was tolerable either. We had good outcome without any additional complication using indirect sealing and suggests this method as an alternative for the complicated dural repair cases.

\section{CONCLUSION}

Spine surgeon should be cautious of incidental durotomy and consider root herniation/entrapment if the patient complains of intractable pain after surgery among other postoperative complications. As in our case, indirect dural repair using Gore-tex ${ }^{\circledR}$ graft and DuraSeal ${ }^{\mathrm{TM}}$ sealant may be a good option for ventral dural repair.

\section{REFERENCES}

1. Ahn Y, Lee HY, Lee SH, Lee JH : Dural tears in percutaneous endoscopic lumbar discectomy. European Spine Journal : Official Publication of the European Spine Society, the European Spinal Deformity Society, and the European Section of the Cervical Spine Research Society 20 : 58-64, 2011

2. Akhaddar A, Boulahroud O, Boucetta $\mathrm{M}$ : Nerve root herniation into a calcified pseudomeningocele after lumbar laminectomy. The Spine Journal : Official Journal of the North American Spine Society 12 : 273, 2012

3. Bae JS, Pee YH, Jang JS, Lee SH : Clinical and radiological findings of nerve root herniation after discectomy of lumbar disc herniation. Journal of Korean Neurosurgical Society $52: 62-66,2012$

4. Bosacco SJ, Gardner MJ, Guille JT : Evaluation and treatment of dural tears in lumbar spine surgery : a review. Clinical orthopaedics and related research : 238-247, 2001

5. Brantigan JW, Steffee AD, Lewis ML, Quinn LM, Persenaire JM : Lumbar interbody fusion using the Brantigan I/F cage for posterior lumbar interbody fusion and the variable pedicle screw placement system : two-year results from a Food and Drug Administration investigational device exemption clinical trial. Spine 25 : 1437-1446, 2000

6. Cammisa FP Jr, Girardi FP, Sangani PK, Parvataneni HK, Cadag S, Sandhu HS : Incidental durotomy in spine surgery. Spine 25 : 2663-2667, 2000

7. Dafford EE, Anderson PA : Comparison of dural repair techniques. The Spine Journal : Official Journal of the North American Spine Society 15 : 1099-1105, 2015

8. Ducati LG, Silva MV, Brandao MM, Romero FR, Zanini MA : Intradural lumbar disc herniation : report of five cases with literature review. European Spine Journal : Official Publication of the European Spine Society, the European Spinal Deformity Society, and the European Section of the Cervical Spine Research Society 22 Suppl 3 : S404-S408, 2013

9. Jones AA, Stambough JL, Balderston RA, Rothman RH, Booth RE Jr : Long-term results of lumbar spine surgery complicated by unintended incidental durotomy. Spine 14 : 443-446, 1989

10. Khan MH, Rihn J, Steele G, Davis R, Donaldson WF, 3rd, Kang JD, et al. : Postoperative management protocol for incidental dural tears during degenerative lumbar spine surgery : a review of 3,183 consecutive degenerative lumbar cases. Spine $31: 2609-2613,2006$

11. Papavero L, Engler N, Kothe R : Incidental durotomy in spine surgery : first aid in ten steps. European Spine Journal : Official Publication of the European Spine Society, the European Spinal Deformity Society, and the European Section of the Cervical Spine Research Society 24 : 2077-2084, 2015

12. Ruban D, O'Toole JE : Management of incidental durotomy in minimally invasive spine surgery. Neurosurgical Focus 31 : E15, 2011

13. Selznick LA, Shamji MF, Isaacs RE : Minimally invasive interbody fusion for revision lumbar surgery : technical feasibility and safety. Journal of spinal disorders \& techniques $22:$ 207-213, 2009

14. Senker W, Meznik C, Avian A, Berghold A : The frequency of accidental dural tears in minimally invasive spinal fusion techniques. Journal of neurological surgery Part A, Central European neurosurgery 74 : 373377,2013

15. Sin AH, Caldito G, Smith D, Rashidi M, Willis B, Nanda A : Predictive factors for dural tear and cerebrospinal fluid leakage in patients undergoing lumbar surgery. Journal of neurosurgery Spine 5 : 224-227, 2006

16. Telfeian AE, Reiter GT, Durham SR, Marcotte P : Spine surgery in morbidly obese patients. Journal of neurosurgery $97: 20-24,2002$

17. Than KD, Wang AC, Etame AB, La Marca F, Park P : Postoperative management of incidental durotomy in minimally invasive lumbar spinal surgery. Minimally invasive neurosurgery : MIN 51 : 263-266, 2008

18. Toppich HG, Feldmann H, Sandvoss G, Meyer F : Intervertebral space nerve root entrapment after lumbar disc surgery. Two cases. Spine 19 : 249-250, 1994 